\title{
O USO DE TECIDOS COMO RECURSO NO PSICODRAMA CLÍNICO E SOCIOEDUCACIONAL
}

\author{
Vanessa Ramalho Ferreira Strauch ${ }^{1,2, *}$ (D), José Murilo Oliveira Santana² (D)
}

\begin{abstract}
RESUMO
Este estudo objetiva descrever a potência do método sociopsicodramático a partir do uso dos tecidos como recurso na investigação e intervenção clínica e socioeducacional. Caracteriza-se como estudo de múltiplos casos, de natureza qualitativa, dados coletados e registrados de dois prontuários clínicos e do diário de campo de sociodramas realizados com educadores e sala de espera de uma clínicaescola de fisioterapia. Identificamos o uso do tecido como eficaz recurso facilitador para aquecimento, redução da tensão e estados de alarme, estabelecimento de vínculos, comunicabilidade não verbal, visualização global da produção concretizada, promover mudança de percepção, relaxamento, oportunizar a emergência dos dramas vividos e dos papéis pouco desenvolvidos.
\end{abstract}

PALAVRAS-CHAVE: Imagem psicodramática; Objeto intermediário; Objeto intraintermediário; Psicodrama.

\section{THE USE OF TISSUES AS A RESOURCE IN CLINICAL AND SOCIOEDUCATIONAL PSYCHODRAMA}

\begin{abstract}
This study aims to describe the power of the sociopsychodramatic method from the use of tissues as a resource in clinical and socioeducational investigation and intervention. It is characterized as a study of multiple cases, of a qualitative nature, data collected and recorded from two clinical records and from the sociodrama field diary conducted with educators and in the waiting room of a physiotherapy clinic-school. We identified the use of fabrics as an effective facilitating resource for warming up, reducing tension and alarm states, establishing links, non-verbal communicability, in the global visualization of the production achieved and promoting change in perception, relaxation, providing opportunities for the emergence of experienced dramas and undeveloped roles.
\end{abstract}

KEYWORDS: Psychodramatic image; Intermediate object; Intraintermediary object; Psychodrama.

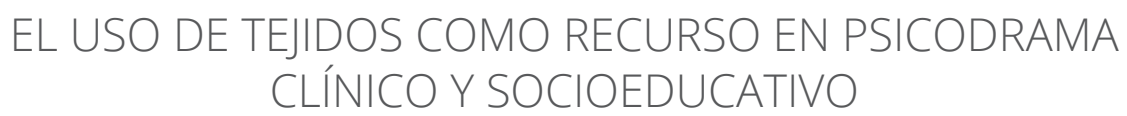

\section{RESUMEN}

Este estudio tiene como objetivo describir el poder del método sociopsicodramático a partir del uso de los tejidos como recurso en la investigación e intervención clínica y socioeducativa. Se caracteriza por ser un estudio de casos múltiples, de carácter cualitativo, datos recogidos y registrados de dos historias clínicas y del diario de campo de sociodramas realizado con los educadores y la sala de espera de una escuela-clínica de fisioterapia. Identificamos el uso de la tela como un recurso facilitador efectivo para el calentamiento, la reducción de tensiones y estados de alarma, el establecimiento de vínculos, la comunicabilidad no verbal, la visualización global de la producción lograda, la promoción del cambio de percepción, la relajación, brindando oportunidades para el surgimiento de dramas experimentados y roles sin desarrollar.

PALABRAS-CLAVE: Imagen psicodramática; Objeto intermedio; Objeto intra-intermediario; Psicodrama.

1.Profissionais Integrados Ltda - Aracaju (SE), Brasil.

2.Universidade Tiradentes $\mathrm{R}$ - Faculdade de Psicologia - Clínica - Aracaju (SE), Brasil.

*Autora correspondente: ramalhonessa@gmail.com

Recebido: 22 Jun. 2020 | Aceito: 18 Jul. 2021

Editor de seção: Marlene Magnobosco Marra 


\section{INTRODUÇÃO}

Uma sessão psicodramática ou sociodramática em grupo possui uma estrutura de procedimentos pautadas em três contextos (social, grupal e dramático), três etapas (aquecimento, dramatização ou jogo central e compartilhamento) e cinco instrumentos (protagonista/cliente, cenário, ego auxiliar, diretor/terapeuta e plateia) (Rojas-Bermúdez, 2016). Entretanto, como assinala Cukier (1992), na clínica bipessoal há a ausência da plateia e do ego auxiliar, que são substituídos, geralmente, por almofadas ou outros objetos. Na prática percebe-se que o diretor também pode vir a assumir esses papéis, representando os outros significativos do cliente e atuando como caixa de ressonância.

Independentemente de o ato psicodramático ser em grupo ou bipessoal, o aquecimento constitui-se um dispositivo potente e crucial, pois prepara os participantes para a dramatização ou o jogo central. As estimulações e sensações proporcionadas pelos aquecimentos concentram a atenção do cliente ou do grupo para o aqui-e-agora, permite emergir o protagonista e o projeto dramático a ser dramatizado, além, de despertar a centelha da espontaneidadecriatividade (Almeida, 1993; Davoli, 1999; Rojas-Bermúdez, 2016); caso isso não ocorra, a sessão poderá sofrer influências negativas e aumentar os bloqueios de contato, principalmente para aqueles com maior dificuldade de se expressar e com timidez excessiva.

Vasconcellos (2007) explana as dificuldades encontradas por psicodramatistas ao se depararem com clientes travados, silenciosos, com dificuldade de se expressar, tímidos e passivos no processo terapêutico, e sugere o uso de recursos para aquecê-los. Nessa perspectiva, o uso do objeto intermediário (OI), descrito por Rojas-Bermúdez (2016) nas décadas de 1970-80, pode ser feito para aquecer o cliente ou o grupo inserindo um objeto no campo de visão quando eles estão inibidos, quando falta comunicação verbal ou há algum estado de tensão, pois um objeto posto no campo visual do protagonista possibilita mobilizar sentimentos e emoções não expressas, por meio dele é possível criar personagens livremente, reduzir o desencadeamento de reações de alarme inesperado e possibilitar a emergência da comunicação. O objeto, segundo Rojas-Bermúdez (1997), pode ainda funcionar como intraintermediário (OII), ou seja, o cliente direcionar sua atenção para a manipulação e a interação direta com o objeto saindo do campo visual para o tátil.

Verificamos que OIs e OIIs têm sido utilizados nos mais diversos contextos, tanto clínicos (Khouri, 2008; Machado, 2008; Rebouças, 2008; 2012), como também em instituições de educação, organizacionais e da saúde (Altarugio, 2019; Rosas \& Carioca, 2017; Souza \& Cassane, 2016), do mesmo modo que se tem utilizado os mais variados tipos de materiais.

Como recurso de OI e OII, Rebouças (2008) utilizou na clínica psicodramática, com uma criança com transtorno global do desenvolvimento, fantoches que possibilitaram a comunicação entre terapeuta e protagonista, ambos atuando e observando a própria criação, e contribuíram, através do jogo de papéis com eles, para a organização dos processos internos.

Em uma organização não governamental que trabalha com ações humanizadas e atendimento à população portadora do IST/HIV/AIDS, Rosas e Carioca (2017) propuseram uma intervenção psicodramática com voluntários utilizando músicas, expressão corporal e jogos como OI, na qual, observou-se que o OI possibilitou fixar a atenção do grupo, diminuir o estado de tensão, propiciou aos participantes acessarem conteúdos e comunicá-los sem inibições ou retraimento.

Em escolas públicas, Souza e Cassane (2016) desenvolveram um projeto sobre a saúde dos educadores com três encontros com professores, gestores e equipe de apoio utilizando como OIs uma pérola, um pingente na forma de pé e, por último, um marcador de livro com uma frase a ser completada. Observou-se que durante as ações a comunicação foi fluida e organizada, oportunizou a tomada de consciência com relação aos comportamentos cristalizados e a possibilidade de melhorar os vínculos. Percebe-se a importância do uso do OI na quebra de gelo, na flexibilização de resistências e no aquecimento para a ação.

O uso de tecido como OI e OII pode ser observado nos trabalhos clínicos de Khouri (2008) com adultos, adolescentes e grupos organizacionais e os de Rebouças (2012) com púberes, nos quais relatam experiências usando 
a técnica de construção de imagens com tecidos (CIT) e os valores terapêuticos como oferecer um campo relaxado para expressar o mundo subjetivo. Almeida e Barasuol (2018) reforçam o uso do psicodrama como ferramenta terapêutica de promoção à saúde, em especial durante a hospitalização. Nesse caso, percebemos o quanto o uso de objetos intermediários é salutar, pois possibilitam diferentes formas de expressão para acamados.

Em uma supervisão com estagiários de Licenciatura em Química utilizando o método educacional psicodramático (MEP) com tecidos, Altarugio (2019) sinaliza que a vivência oportunizou aos licenciandos concretizarem as emoções que os atravessavam ao refletir sobre as escolas, as práticas e os conflitos, além da tomada de consciência das potencialidades das instituições de ensino onde faziam estágios.

O interesse no estudo teórico-metodológico do uso de tecidos no psicodrama teve início com ações realizadas pelo presente coautor no campo de estágio em psicologia da saúde e em um projeto de extensão em psicologia escolar. Na ocasião, o material foi inserido nas ações sociodramáticas de modo intuitivo. Após supervisões junto à coautora e diante da necessidade de escrever relatórios, conheceu o conceito de OI, OII e a CIT - ampliando assim o escopo das ferramentas a serem utilizadas para representação de subjetividades a partir da própria construção de imagens moreniana com o uso do próprio corpo no palco, por exemplo. Moreno et al. (2001) citando o filósofo surrealista Breton em 1949, concorda que

\footnotetext{
é na surpresa criada por uma nova imagem ou por uma nova associação de imagens que épreciso ver o elemento mais importante do progresso das ciências físicas, pois é o espanto que excita a lógica, sempre bastante fria, e a obriga a estabelecer novas coordenações.
}

Tal momento de surpresa junto ao contato com o mundo simbólico das imagens pode levar à transição de um estado a outro, uma mudança. O uso de objetos mais ou menos estruturados numa representação conflitiva instiga a fluência de espontaneidade e criatividade que tornará os indivíduos mais saudáveis e sapientes nas soluções dos problemas e no lidar com as conservas culturais de forma não congelante.

Posteriormente, em estágio clínico universitário, na abordagem psicodramática, devido à escassez de almofadas ou outros objetos, a resposta mais adequada e disponível no momento da situação foi usar os tecidos como um recurso material desde a construção de imagens até no desenvolvimento dos jogos de átomo social, familiar e de queixas, e esquemas de papéis. De lá para cá o coautor tem-se empenhado em aprofundar e compreender a multiplicidade no uso e na potência terapêutica dos tecidos nos diversos contextos psicodramáticos.

Esse cenário nos estimulou a escrever este trabalho para partilhar com os psicodramatistas nosso empreendimento vivenciado em atualizar a produção científica da temática e convidá-los a refletir conosco as multiplicidades criativas e terapêuticas oportunizadas pelo uso dos tecidos como recurso psicodramático não apenas na clínica, como também nos contextos socioeducacionais (institucionais e comunitários). Este estudo objetiva descrever a potência do método sociopsicodramático a partir do uso dos tecidos como recurso na investigação e intervenção clínica e socioeducacional.

\section{MÉTODOS}

Este artigo caracteriza-se como estudos de múltiplos casos, de natureza qualitativa (Alves-Mazzotti, 2006), com dados coletados e registrados em prontuários clínicos de dois clientes em psicoterapia psicodramática bipessoal e do diário de campo institucional de duas vivências sociodramáticas.

Os quatro casos foram desenvolvidos a partir do referencial socionômico. As sessões e as vivências apoiaram-se nas etapas de aquecimento, ação dramática e compartilhamento. Além dos tecidos, baseamo-nos nos cinco instrumentos do psicodrama: protagonista, diretor, ego auxiliar, cenário e plateia. No contexto clínico, os instrumentos utilizados foram o protagonista-cliente, diretor-terapeuta, cenário e tecidos. Já nas vivências socioeducacionais, os instrumentos 
foram o protagonista-grupo, diretor, ego auxiliar, cenário, plateia-público e tecidos. Fundamentamo-nos nos estudos de Cukier (1992) e Rojas-Bermúdez (1997; 2016).

Ressaltamos que este estudo focaliza na utilização de tecidos como recurso na prática psicodramática dos contextos clínico e socioeducacional na educação e na saúde, em suas aplicabilidades, bem como nos resultados da intervenção e seus efeitos na espontaneidade e criatividade, sem ampliar para outros aspectos históricos das pessoas ou grupos envolvidos.

\section{Análise dos dados e aspectos éticos}

A análise textual discursiva de Moraes e Galiazzi (2016) foi utilizada como método de análise de dados por possuir bases epistemológicas próximas à socionomia: a fenomenologia, o existencialismo e a hermenêutica. Assim, realizamos leitura do prontuário e dos diários de campos, expomos as unidades de significado, que foram agrupas a partir da relação e/ou da aproximação de significados contidos entre elas, formando categorias iniciais e depois reagrupadas em três categorias finais.

Vale ressaltar que os sujeitos envolvidos nos casos estão resguardados quanto à integridade, ao sigilo das informações, à preservação da identidade com nome fictício, tiveram participação voluntária e assinaram o Termo de Consentimento Livre e Esclarecido (TCLE), conforme previsto pelas Resoluções no 466/12 e 510/16 do Conselho Nacional de Saúde (Brasil 2013; 2016).

\section{Caso 1: Clínica psicodramática bipessoal - “Maria”}

Cliente: Maria, 19 anos, gênero feminino, universitária, procurou o serviço de clínica-escola de psicologia por causa de sinais de ansiedade e da emergência de episódio de pânico ao entrar no ônibus coletivo e durante uma prova.

Situação e procedimentos: dificuldades em expressar os sentimentos e de entrar em contato com o mundo interno, de defletir os assuntos com situações superficiais do cotidiano, além da postura passiva e não trazer conteúdo para ser trabalhado. Assim, usamos os tecidos na sessão $\mathrm{n}^{\circ} 2$ com a construção de um átomo de queixas (adaptação do átomo social substituindo os eus significativos por queixas); nas sessões 6,7 e 8 com a construção do esquema de papéis a partir de um capítulo de livro trazido pela cliente; e na sessão 9 com a CIT (Khouri, 2008). Ademais, as técnicas empregadas nessas sessões foram autoapresentação, entrevista no papel, solilóquio, espelho, duplo, inversão de papéis e concretização (Cukier, 1992).

\section{Caso 2: Clínica psicodramática bipessoal - “João”}

Cliente: João, 38 anos, gênero masculino, empregado, em relacionamento heteroafetivo e heterossexual, buscou a psicoterapia por motivos de autoconhecimento, para "sair da caixinha [sic]" e por ser "dramático".

Situação e procedimentos: o cliente apresentava comportamento cristalizado, silencioso, dificuldade de falar sobre si, dava respostas curtas, tinha postura passiva e de espera constante pela iniciativa do terapeuta. Desse modo, os tecidos foram inseridos nas sessões 2, 6 e 7, nas quais utilizamos a CIT (Khouri, 2008); e um átomo de queixas (adaptação temática do átomo social associado ao levantamento e análise de relevância e sociometria das queixas) foi construído na sessão 8 . Todas as sessões foram auxiliadas pelas técnicas de autoapresentação, entrevista no papel, inversão de papéis, maximização, solilóquio, duplo e concretização (Cukier, 1992).

\section{Caso 3: Sociodrama em sala de espera}

Participantes: acompanhantes de pacientes em reabilitação fisioterapêutica. Sete mulheres e dois homens, um diretor e dois egos auxiliares.

Situação e procedimentos: grupo de apoio do tipo aberto, com alta rotatividade, com dificuldade na vinculação entre os participantes e baixa adesão. Além disso, os participantes eram tímidos, com dificuldade de se expressar e de falar em 
público. Em uma das intervenções o tema "valorização da vida" foi tratado durante a campanha do Setembro Amarelo, em uma sala de espera da clínica-escola de fisioterapia. Aquecimento inespecífico: com os participantes em roda, foi solicitado que olhassem para alguém do grupo e fossem em direção a ele. A pessoa observada, ao perceber a chegada da observadora, deveria olhar para outro membro e ir em direção a ele. Aquecimento específico: foi instruído que escrevesse em um papel uma mensagem para alguém que estava em sofrimento e que, por algum motivo, não pode receber a frase. Em seguida, que observassem os tecidos e escolhessem aquele que tivesse alguma representação com a frase ou a pessoa pensada. Depois, que fizessem alguma forma com os tecidos e os depositassem perto de uma árvore. Por fim, que observassem cada mensagem e forma produzida pelo grupo. Seguimos com o compartilhamento.

\section{Caso 4: Sociodrama em reunião pedagógica}

Participantes: sete professoras e uma coordenadora do programa Educação para Jovens e Adultos (EJA) de uma escola estadual, um diretor e três egos auxiliares.

Situação e procedimentos: intervenção encomendada pela coordenadora pedagógica com o objetivo de traçar temas a serem trabalhados com os alunos durante o semestre letivo. Na sala foram espalhados tecidos e novelos de linha. Após o relaxamento guiado, as educadoras construíram uma árvore com os materiais disponíveis na sala. Em seguida, foram distribuídos dois pedaços de papéis para cada participante com a instrução de escrever no papel branco algo que elas poderiam fazer pelos alunos e no papel colorido os temas que seriam trabalhados no semestre. Além disso, deveriam colocar os escritos em alguma parte da imagem criada coletivamente com os tecidos. Seguimos com o compartilhamento.

\section{RESULTADOS}

Optou-se por apresentar os resultados através de categorias que apontam a potência do uso do tecido como recurso psicodramático em vez de recortes de caso por caso. Assim, são descritas três possíveis potencialidades do recurso que emergiram nos casos estudados: 1) estabelecer a comunicação e a vinculação; 2) revelar conflitos e papéis encobertos e 3) mobilizar sentimentos, reflexão e mudança de percepção.

\section{Estabelecer a comunicação e a vinculação}

A partir da dificuldade de Maria e João em falar sobre o que os incomodavam e os motivos que os levaram a buscar terapia, foi proposto aos clientes que observassem os tecidos dispostos e montassem um átomo de queixas, dando formas com uma ou mais texturas e cores, caso desejassem. Com isso, a atenção se voltou para o jogo, o estado de tensão e o retraimento reduziram, e os clientes foram comunicando os dramas enfrentados no cotidiano.

Com a inserção dos tecidos no jogo do átomo de queixas, eles vão modelando e representando as mágoas, os aborrecimentos, as preocupações e as angústias existenciais distanciando-as ou aproximando-as do eu representado a partir de quanto incômodo estava gerando. Após um distanciamento da criação, dão nomes às formas e buscam compreender as relações existentes. Assim, dentre as queixas de Maria emergiram: as relações afetivo-sexuais e de amizades, ansiedade "na minha cara" [sic], pegar ônibus, a identidade visual, a interferência da família e não gostar da cor rosa. No jogo de João apresentam-se como temas protagônicos: melhorar as finanças, novos projetos, melhorar a relação com a parceira e com os familiares (mãe, irmão e irmã — afastamento sociométrico), fechar ciclos e desenvolver o papel da gana (ambição).

No grupo de acompanhantes na sala de espera da clínica-escola de fisioterapia, devido ao histórico de ser um grupo de apoio do tipo aberto, com alta rotatividade, com dificuldade na vinculação entre os participantes e baixa interação, a inserção do tecido no aquecimento oportunizou que os participantes expressassem os sentimentos e as opiniôes que envolviam a valorização da vida e as dificuldades enfrentadas no cuidado do ente que se encontra com alguma limitação motora temporária ou permanente, leve ou grave. 
Relacionar as cores e as formas no tecido com a frase possibilitou emergirem pensamentos e sentimentos como “andar e não parar porque você sempre continuará de pé”, “você é importante”, “força, você consegue!” e "tenha muita fé, no final tudo vai dar certo".

No sociodrama com educadores, observamos que a técnica de CIT oportunizou a construção coletiva de uma hipótese situacional dos alunos do EJA, uma vez que, para as educadoras, os principais conflitos e desconforto na escola durante o período noturno residem na comercialização de drogas ilícitas, na drogadição e na violência por parte do alunado; ainda, existe a falta de autoestima de alunos, justificada pelas participantes, pelo fato de as turmas serem formadas por jovens e adultos que trabalham, alguns casados, outros com filhos, desempregados, sem interesse para os estudos e sem perspectiva de futuro.

Verificamos que as palavras autoestima, drogas e relaçôes interpessoais foram colocadas na raiz da árvore fazendo alusão à raiz do problema. Ainda, a cultura da paz fixada entre o tronco e a copa como sendo a sustentação necessária para dar bons frutos na educação.

\section{Revelar conflitos e papéis encobertos}

Do esquema de papéis construído por Maria — ampliado para além de seus papéis sociais — emergiram das formas e cores dos tecidos os eus nomeados de Insegurança, Insuficiente, Água, Mudança, Ansiosa, a Ouvinte próximos do tecido azul (Maria integral) e os papéis mais afastados Falante, a Passiva-agressiva, o Sentimentalismo e o Romantizar.

$\mathrm{Na}$ história de Maria, um cuidado excessivo por parte dos pais da protagonista por medo de perder a filha única, ou seja, o vínculo dos papéis Insegurança-Controle (Maria-pais) era o mais experimentado pela cliente. O Eu Inseguro, tão presente no vínculo assimétrico com os papéis familiares de Maria, tem se repetido na interação com outras relações, o que pode sugerir um cluster de papéis ou um fio condutor transferencial comum entre os papéis.

Em uma CIT mobilizada pelo término do vínculo amoroso e com dificuldade de falar sobre a cena, João construiu uma imagem com céu, arco-íris, casulo, borboleta e jardim. Após se distanciar e comentar a produção, o cliente entrou no papel da Borboleta e do Jardim. Assim, na fala do cliente no papel do Jardim (que posteriormente foi compreendido pelo protagonista como sendo o Ser Cuidado) emergiu um possível conflito entre papel versus contrapapel - Cuidador versus Ser Cuidado - papéis esses que irão emergir em sessões posteriores e que estão intimamente ligados aos tipos de vínculos estabelecidos nos relacionamentos amorosos do cliente e nos conflitos sociométricos com os familiares, aparentemente tendo o papel de Cuidador pouco desempenhado.

João, que por questões da própria história de vida e ser-no-mundo não havia conseguido desenvolver o papel de Cuidador, percebeu que seus papéis cristalizados têm promovido vínculos assimétricos de dependência emocional com a companheira e conflitos com os familiares que não desempenham os papéis exigidos por ele.

\section{Mobilização de sentimentos, reflexão e mudança de percepção}

Dar forma, cor e nome aos conflitos e se distanciar dos dramas que emergiram no aqui-e-agora para observálos de fora oportunizaram a mudança de percepção da situação atual. Maria, ao selecionar cores, texturas e dar formar às queixas e se distanciar da produção, percebe-se encurralada entre a parede e os conflitos e menciona sentir-se sufocada. João, ao dialogar com as queixas, percebe que tem muitas ideais, mas não planeja nem executa ao constatar o medo de não darem certo.

Em uma sessão, João informa que a parceira havia terminado o relacionamento. Permanecia em silêncio por tempos, dava respostas curtas, hesitava em falar sobre os sentimentos. O cliente construiu uma imagem com tecido para expressar o sentimento, deu-lhe o nome de Embrolho e, ao observá-la, mencionou sobre os obstáculos da vida, das curvas tortuosas por onde passara, do término, culpava-se e não sabia o que fazer. Uma imagem associada a sentimentos conflitivos pressupõe o estímulo à ação. Solicitamos que fizesse outra imagem que representasse o 
dali para frente e deu-lhe o nome de Amanhã, a qual falava sobre seguir em frente e ir atrás dos objetivos. Após entrevista no papel e inversão de papéis, João, que se sentia embrulhado com o término, ao fim da sessão dizia sentir-se aliviado.

Maria construiu duas imagens com tecidos, uma sobre como se sentia em relação aos amigos, e a outra sobre os relacionamentos, cobrindo ambas com um grande tecido. À medida que as figuras receberam nomes, foram apresentadas e vistas de longe, um jogo de papéis foi formado entre a cliente, as Relaçôes-de-amizade e a Insegurança. Ao fim, Maria foi convidada a dar um novo desfecho àquele drama, visto que, no como-se psicodramático, podemos passar do como foi e como é para uma experimentação do como poderia ser ou como desejaria que fosse. Assim, Maria coloca a Insegurança, que emergiu na cena entre as Relaçóes-de-amizade e as Relaçóes-amorosas, e o tecido que os encobria é retirado parcialmente de cima dando espaço para que as relações começassem a aparecer.

No sociodrama com os acompanhantes, os tecidos facilitaram a comunicação e estabeleceram a vinculação entre os participantes de tal modo que Dona Ana sentiu-se mobilizada e revelou seu drama: a exclusão que familiares e amigos cometem em relação ao neto que tem deficiência cognitiva e física; a tristeza quando parentes dizem que o neto na escola é gasto de dinheiro e que não tem solução para o problema do garoto. Carla evoca uma das frases escrita por Dona Ana: “andar e não parar por que você sempre continuará de pé”, e começa a mencionar algumas qualidades do garoto, outros participantes começam a fazer o mesmo. A avó menciona que continuará buscando o melhor para o neto independente do que os familiares pensam. A trama ilustrada pelos tecidos revelou as identificações existenciais presentes.

No grupo de educadoras, a construção de imagem com tecidos serviu como dispositivo potente para refletir a implicação delas no processo educacional e manifestar a subjetividade coconsciente e coinconsciente. $O$ fazer educação é mais que ensinar as disciplinas curriculares, é necessário Escuta; Ouvir, conversar e orientar; e valorizar o aluno e as diferenças, estas foram as palavras fixadas pelas participantes na árvore.

\section{DISCUSSÃO}

No trabalho psicodramático clínico ou socioeducacional o terapeuta ou a direção buscará possibilidades de romper as travas e, concomitantemente, coconstruir caminhos que convidem os protagonistas com dificuldades de agir, expressar-se, falar sobre si, silenciosos e tímidos para um processo ativo, em movimento e corresponsável pelas criações existenciais (Vasconcellos, 2007).

Nessa perspectiva, verificamos que os tecidos foram iniciadores do aquecimento de Maria, João e dos dois grupos quando estavam inibidos, com pouca comunicação verbal ou algum estado de tensão, isso pois, ao serem postos no campo visual do protagonista e do grupo, possibilitaram emergir as principais queixas e promoveram a interação entre terapeuta-cliente e direção-grupo. A partir da maior mobilização interacional e télica com o despertar espontâneo criativo, o recurso simbólico pôde resgatar questões mais inconscientes e cristalizadas.

No grupo de educadores e cuidadores constatamos que os tecidos funcionaram como OI ao aquecerem o grupo para o aqui-e-agora e para a comunicação emergir, uma vez que o material atuou como extensão dos participantes, ou seja, o tecido (imagem) fala pelo protagonista. Já nos casos clínicos, os tecidos passaram de extensão para o jogo de interação em que a atenção foi dividida entre o si mesmo e o objeto, para aprofundar a reflexão, assim a função de OI move-se para OII (Rojas-Bermúdez, 1997; 2016).

Estudos clínicos de psicodrama bipessoal com a técnica CIT realizados por Rebouças (2012) com púberes mostraram-se favoráveis, justamente pelo fato de o recurso oferecer um campo relaxado propício para expressão do mundo subjetivo. A autora informa que na fase da puberdade existem várias mudanças fisiológicas, mentais e socioafetivas que colocam o adolescente em estado de tensão impendido que o protagonista se volte para o eu.

A utilização de OI em psicodrama socioeducativo possibilita que o grupo foque a atenção para o aqui-e-agora, diminuindo o estado de tensão, proporcionando aos participantes acessarem conteúdos internos e comunicá-los de modo fluido e organizado, sem inibições ou retraimento, ainda oportuniza a tomada de consciência em relação aos 
comportamentos cristalizados e a possibilidade de melhorar os vínculos (Rosas \& Carioca, 2017; Souza \& Cassane, 2016). Além disso, percebemos a contribuição do OI na manutenção do foco.

Esse fenômeno ocorre pelo fato de os tecidos funcionarem como OI e OII de comunicação, o tecido é um objeto real e concreto que intermedia as dificuldades de comunicação entre terapeuta-cliente, cliente-consigo mesmo, diretor-grupo e grupo-grupo, estabelece e estreita vínculos e externaliza os sentimentos por reduzir o estado de tensão e alerta (Marengo, 2015).

A inserção e a manipulação dos tecidos no cenário possuem influência em atrair a atenção e favorecer o processo de aquecimento (Rojas-Bermúdez, 2016). Este último, como uma matriz de criação, instrumentaliza e prepara o protagonista ou o grupo para a cocriação de atos espontâneos e criativos (Davoli, 1999).

Ainda, podemos compreender os tecidos como iniciadores fisiológicos (neste trabalho com foco nos visuais e táteis) utilizados tradicionalmente no aquecimento. Conforme Almeida (1993), as estimulações sensoriais sensibilizam e mobilizam as emoções dos protagonistas, colocando-os no momento presente.

Além de funcionarem como iniciadores no aquecimento, os tecidos operaram como uma ponte entre o mundo e o papel mal desenvolvido que estavam encobertos pelo si mesmo, contribuindo para criar e manter um jogo entre papel e contrapapel, como no caso do role-playing de Cuidador versus Ser-cuidado de João e das Relaçóes-de-amizade versus Insegurança de Maria, além de possibilitar emergirem os dramas vividos como na relação familiar desta e do relacionamento afetivo-sexual de João.

Acontece que o núcleo do eu é revestido por uma espécie de membrana denominado de si mesmo que funciona como protetora do mundo circundante e do estabelecimento de vínculos geradores de conflitos, porém ele não é fixo. À medida que o protagonista relaxa ou por meio dos aquecimentos psicodramáticos, o si mesmo contrai-se podendo chegar próximo do eu, o desencadeamento de reações de alarme é reduzido, oportuniza a emergência de papéis poucos desenvolvidos e dos conflitos evitados que estão dentro da área do si mesmo (Rojas-Bermúdez, 2016).

A CIT possibilita que a objetivação do mundo interno torne-se visível no cenário e, ao congelar a situação concretizada, permite que o protagonista se distancie da criação para observá-la a partir de outros ângulos e dê-se conta das suas vivências (Khouri \& Machado, 2008), como Maria que se percebe encurralada entre a parede e os conflitos ao observar o átomo de queixas ou como os professores que identificaram através da construção da árvore as raízes dos problemas da educação no EJA e qual a sustentação necessária para produzir bons frutos. Nas representações simbólicas do conflito (interno-externo), sejam imagéticas ou dramáticas, percebemos a importância das técnicas morenianas de visão panorâmica e de zoom, pois vendo de fora ou vendo de dentro da situação, novas percepções são experienciadas, insights são promovidos e associados à ação numa catarse de integração.

Mesmo com condições de espaço, tempo e quantidade de participantes nos dois grupos terem sidos um obstáculo, a oferta de um ato sociodramático com as três etapas e no lugar da dramatização, a CIT mostrou-se favorável. Entretanto observamos que a mobilização e a mudança de percepção oportunizados pela CIT de João (Jardim, o Embrolho e o Amanhã) e Maria (Relaçôes-de-amizade versus Insegurança) foram potencializados quando articulamos com as técnicas psicodramáticas como o duplo, espelho, solilóquio e inversão de papéis (Khouri, 2008). Ou seja, a aplicação das técnicas básicas é uma intervenção promotora de mudança de visão do problema, uma intervenção mais profunda necessária para uma atuação mais saudável diante da situação-problema.

A imagem psicodramática é um trabalho estático, e a dramatização, dinâmica. Entretanto uma não é oposição da outra, mas uma complementaridade. Assim, no palco psicodramático pode-se iniciar com a construção de imagem e em seguida dramatizá-la ou vice-versa (Khouri \& Machado, 2008).

\section{CONCLUSÃO}

Ambos juntos, o método do psicodrama e o recurso do tecido, tornaram-se fatores de potencialização da prática de cuidado e produção de mudança ou subjetivação. Nesse sentido, verificamos que o tecido como OI e OII pode ser um recurso valioso para a relação terapeuta-cliente e direção-grupo, pois, ao contribuir com o relaxamento do $s i$ 
mesmo, oportuniza a emergência de papéis pouco desenvolvidos sem que ocasione resistência ou alertas indesejados por parte do protagonista.

É corriqueira a cena do cliente (indivíduo ou grupo) calado, tímido, que hesita na fala, com dificuldade de se expressar e passivo, esperando a atitude do terapeuta. A inserção dos tecidos no campo visual e tátil do(s) sujeito(s) promoveu estabelecer ou reestabelecer o vínculo entre terapeuta-cliente/grupo, insights, restaurar a comunicação interrompida, concretizar os sentimentos não nomeados e também permitiu que conteúdos desconhecidos ou psicodramaticamente rejeitados surgissem.

Como ensina Moreno, criador da socionomia, o produto dessa criação congelar-se-á no tempo, tornando-se uma conserva cultural. Embora ela seja o produto, também é início para uma nova criação. Nessa perspectiva, a construção deste ensaio gerou outras inquietações e questionamentos, afinal, mais importante que o artigo é o que ele produz; os resultados provocam uma centena de perguntas, dentre elas destacamos: como se daria o uso de tecidos e as contribuições em contextos de psicodrama pedagógico nos diversos níveis de educação e formação continuada? Ou ainda: qual a viabilidade do uso de tecidos como instrumento de levantamento de dados nas diferentes formas de pesquisa?

\section{CONTRIBUIÇÃO DOS AUTORES}

Conceptualização: Santana JMO; Cura de Dados: Santana JMO; Metodologia: Santana JMO; Investigação: Santana JMO; Análise Formal: Santana JMO e Strauch VRF; Redação - Primeira versão: Santana JMO e Strauch VRF; Redação - Revisão \& Edição: Santana JMO e Strauch VRF; Supervisão: Strauch VRF.

\section{DISPONIBILIDADE DE DADOS DE PESQUISA}

Todos os conjuntos de dados foram gerados ou analisados no estudo em curso.

\section{FINANCIAMENTO}

Não aplicável.

\section{AGRADECIMENTOS}

Agradecimentos especiais a todas as pessoas que direta e indiretamente participaram das intervenções, incluindo todo pessoal de apoio nas instituições visitadas.

\section{REFERÊNCIAS}

Almeida, B. L. S., \& Barasuol, E. B. (2018). Psicodrama: Um recurso durante a hospitalização. Revista Brasileira de Psicodrama, 26(1), 126-132. https://doi.org/10.15329/2318-0498.20180004

Almeida, W. C. (1993). Os iniciadores. In R. Monteiro (Ed.). Técnicas fundamentais do psicodrama (pp. 32-44). Brasiliense.

Altarugio, M. H. (2019). Método educacional psicodramático como metodologia ativa no contexto do estágio supervisionado. Revista Brasileira de Psicodrama, 27(1), 118-124. https://doi.org/10.15329/0104-5393.20190012

Alves-Mazzotti, A. J. (2006). Usos e abusos dos estudos de caso. Cadernos de Pesquisa, 36(129), 637-651. https://doi. org/10.1590/S0100-15742006000300007

Brasil. Conselho Nacional da Saúde. (2013). Resolução n 466, de 12 de dezembro de 2012. Aprova normas regulamentadoras de pesquisas envolvendo seres humanos. Brasília: Diário Oficial da União. Disponível em: https:// bvsms.saude.gov.br/bvs/saudelegis/cns/2013/res0466_12_12_2012.html. Acesso em: 20 Nov. 2019. 
Brasil. Conselho Nacional da Saúde. (2016). Resolução no 510, de 07 de abril de 2016. Brasília: Diário Oficial da União. Disponível em: http://conselho.saude.gov.br/resolucoes/2016/Reso510.pdf. Acesso em: 20 Nov. 2019.

Cukier, R. (1992). Psicodrama bipessoal: Sua técnica, seu terapeuta e seu paciente. Ágora.

Davoli, C. (1999). Aquecimento: Caminhos para a dramatização. In: W. C. Almeida (Ed.). Grupos: A proposta do psicodrama (77-78). Âgora.

Khouri, G. S. (2008). Construção de imagens com tecidos (CIT) em psicoterapia psicodramática bipessoal e nas organizações. In: H. J. Fleury, F. S. Khouri, \& E. Hug (Eds.). Psicodrama e neurociência: Contribuições para a mudança terapêutica (129-162). Ágora.

Khouri, G. S., \& Machado, M. L. (2008). Imagem psicodramática e a técnica de construção de imagens. In H.J.Fleury, F. S. Khouri, \& E. Hug (Eds.). Psicodrama e neurociência: Contribuições para a mudança terapêutica (77-104). Ágora.

Machado, M. L. (2008). Uso da técnica de construção de imagens na clínica psicodramática. In H. J. Fleury, F. S. Khouri, \& E. Hug (Eds.). Psicodrama e neurociência: Contribuiçōes para a mudança terapêutica (pp. 107-128). Agora.

Moraes, R., \& Galliazzi, M. C. (2016). Análise textual discursiva. Unijuí.

Marengo, M. T. (2015). El Psicodrama como método: Escenificar em psicoterapia desde un enfoque integrativo. Autores de Argentina.

Moreno, Z. T.; Blomkvist, L. D. \& Rützel, T. (2001). A realidade suplementar e a arte de curar. Ágora.

Rebouças, R. M. S. (2008). Os objetos intermediários e intra-intermediários na psicoterapia psicodramática infantil em um caso de transtorno global do desenvolvimento. In H. J. Fleury, F. S. Khouri, \& E. Hug (Eds.). Psicodrama e neurociência: Contribuições para a mudança terapêutica (pp. 163-187). Ágora.

Rebouças, R. M. S. (2012). A técnica de construção de imagem com tecidos no psicodrama com púberes. Revista Brasileira de Psicodrama, 20(2), 141-155.

Rojas-Bermúdez, J. G. (1997). Teoría y técnica psicodramáticas. Paidós.

Rojas-Bermúdez, J. G. (2016). Introdução ao psicodrama. Ágora.

Rosas,E.V.B.,\& Carioca,J.M.G. (2017). Significações atribuídas o ócio nas oficinas psicodramáticas numa organização não governamental. Revista Brasileira de Psicodrama, 25(2), 37-46. https://doi.org/10.15329/2318-0498.20170020

Souza; A. C., \& Cassane, I. T. (2016). O cuidado com a saúde dos professores por meio de Sociodrama e com o uso de objetos intermediários. Revista Brasileira de Psicodrama, 24(1), 69-75. https://doi.org/10.15329/2318-0498.20160009

Vasconcellos, M. C. M. (2007). Reflexões de uma terapeuta sobre o cliente travado. In Quando a psicoterapia trava (pp. 17-28). Ágora. 